\title{
Consent: an event or a memory in lumbar spinal surgery? A multi-centre, multi-specialty prospective study of documentation and patient recall of consent content
}

\author{
William B. Lo ${ }^{1} \cdot$ Ciaran P. McAuley $^{2}$ (D) Martin J. Gillies $^{3} \cdot$ Patrick J. Grover $^{4}$. \\ Erlick A. C. Pereira ${ }^{2,5}$
}

Received: 28 January 2017/Revised: 18 March 2017/Accepted: 18 April 2017/Published online: 20 May 2017

(C) The Author(s) 2017. This article is an open access publication

\begin{abstract}
Study design Prospective, multi-centre, multi-specialty medical notes review and patient interview.

Purpose The consenting process is an important communication tool which also carries medico-legal implications. While written consent is a pre-requisite before spinal surgery in the UK, the standard and effectiveness of the process have not been assessed previously. This study assesses standard of written consent for elective lumbar decompressive surgery for degenerative disc disease across different regions and specialties in the UK; level of patient recall of the consent content; and identifies factors which affect patient recall.

Methods Consent forms of 153 in-patients from 4 centres $\mathrm{a}, \mathrm{b}, \mathrm{c}, \mathrm{d}$ were reviewed. Written documentation of intended benefits, alternative treatments and operative risks was assessed. Of them, 108 patients were interviewed within $24 \mathrm{~h}$ before or after surgeries to assess recall.

Results The written documentation rates of the operative risks showed significant inter-centre variations in haemorrhage and sphincter disturbance $(P=0.000)$, but not for
\end{abstract}

Erlick A. C. Pereira

eacp@eacp.co.uk

1 Department of Neurosurgery, Queen Elizabeth Hospital, Birmingham, Birmingham, UK

2 Academic Neurosurgery Unit, St George's, University of London, London, UK

3 Department of Neurosurgery, John Radcliffe Hospital, Oxford, UK

4 Department of Neurosurgery, Charing Cross Hospital, London, UK

5 Atkinson Morley Wing, St George's Hospital, London SW17 0QT, UK others. Analysis of pooled data showed variations in written documentation of risks $(P<0.0005)$, highest in infection $(96.1 \%)$ and lowest in recurrence $(52.3 \%)$. For patient recall of these risks, there was no inter-centre variation. Patients' recall of paralysis as a risk was highest $(50.9 \%)$ and that of recurrence was lowest $(6.5 \%)$. Patients $<65$ years old recalled risks better than those $\geq 65$, significantly so for infection (29.9 vs $9.7 \%, P=0.027)$. Patients consented $>14$ days compared to $<2$ days before their surgeries had higher recall for paralysis (65.2 vs $43.7 \%$ ) and recurrence (17.4 vs $2.8 \%$ ). Patient recall was independent of consenter grade.

Conclusion Overall, the standard of written consent for elective lumbar spinal decompressive surgery was suboptimal, which was partly reflected in the poor patient recall. While consenter seniority did not affect patient recall, younger age and longer consent-to-surgery time improved it.

Keywords Lumbar · Spinal surgery · Consent · Risks · Medico-legal

\section{Introduction}

The process of consent is an important method to communicate all aspects of the proposed procedure, including benefits and risks, as well as having medico-legal importance. In the UK, the General Medical Council (GMC) specifies guidance on gaining consent from patients for any procedure [1].

Guidance in the UK, and the process of consent, has developed with consequent landmark cases. The Bolam Judgement (1957) stated that a doctor's provision of care and, therefore, consent should be judged to the views of a 
responsible body of doctors [2]. Sidaway v The Bethlem and Maudsley Hospitals (1985) reaffirmed that the standard of information given during consent should be judged using the Bolam Criteria [2, 3]; however, Lord Scarman dissented with this judgement, arguing that disclosure of a risk should occur 'where the risk is such that in the court's view, a prudent person in the patient's situation would have regarded it as significant' [3, 4].

The progression to a more patient-centred approach to consent continued with Lord Woolf's judgement in Pearce v United Bristol NHS Trust (1999). Lord Woolf stated that doctors were responsible to disclose to the patient any 'significant risk, which would affect the judgement of a 'reasonable patient'. In the case of Chester v Afshar (2004), Mr Afshar was found negligent due to his failure to inform of the risk of cauda equina syndrome during the procedure, even though he was found to have performed the operation adequately [5-7]. Ultimately, the decision emphasized the requirement for written documentation of all risks, as although Mr Afshar claimed that he had consented for the risk of cauda equina syndrome, the failure to document led to the judgement in favour of Miss Chester.

The case of Montgomery v Lanarkshire has led now to a further requirement for surgeons to tailor the consent to the individual patient involved, rather than to the procedure $[8,9]$. As a result of the Montgomery ruling, the Royal College of Surgeons has recently issued guidelines for surgeons on the process of gaining consent. Pertinently, these guidelines state that the consent process should be tailored to the individual, all treatment options should be given with their material risks, and that the discussion should be written and recorded on the consent form and elsewhere [10].

Despite the fact that several of these landmark cases were concerning spinal surgery, there has not been any evaluation of the standard or effectiveness of the consent process in spinal surgery. In this study, we evaluate the consent process in spinal surgery both in its written documentation and patient's peri-operative recall of it, including many of the domains covered in the recent Royal College of Surgeon's guidelines.

\section{Methods}

\section{Study design}

Subjects enrolled in the present study were all in-patients between September and November 2008 in four centres (neurosurgery departments in Oxford, Birmingham, Charing Cross Hospital London, and an orthopaedic department in Oxford), with a primary diagnosis of degenerative lumbar disc disease who were $24 \mathrm{~h}$ pre- or post-elective lumbar decompressive surgeries, such as laminectomy and discectomy. Adults of all ages were included. Patients undergoing revision surgeries were included. Patients undergoing instrumentation surgeries were excluded.

\section{Review of written documentation}

153 written consent forms (together with case notes) were reviewed. The intended benefits, alternative treatments, and operative risks were recorded. To evaluate the sufficiency of documentation of intended benefits, improvement in pain (or discomfort) and improvement (or prevention of deterioration) in mobility were chosen. To evaluate that of alternative treatments, physiotherapy and epidural injection were used. For risks and complications, the following six sequelae were evaluated: paralysis, sphincter disturbance (or cauda equina syndrome), infection, haemorrhage, dural tear (or cerebrospinal fluid leak), and recurrence.

\section{Patient interview}

Where available, patients were interviewed after written consent and within $24 \mathrm{~h}$ before or after their surgeries. The open questions asked are listed in Table 1.

\section{Statistical analysis}

To assess the level of patient recall, the percentage is calculated by dividing the number of patients who recalled a particular risk unprompted by the total number of patients interviewed. By doing so, those patients who have been informed about certain risks which for one reason or another were not documented on the form would still be included. It also represents the definitive outcome of the consent process, regardless of its quality.

The null hypotheses for this study were that the documented intended benefits and operative risks for lumbar decompressive surgery across regions and specialties were not different from one another; patient recall from different centres was not different; consenter seniority, age of patients, and timing of consents did not affect patient recall. For categorical variables, comparisons were calculated using SPSS software to perform 2-tailed Fisher exact tests and two-sided McNemar tests. Continuous data, i.e., age of patients and time between consent and surgery, were divided into groups, i.e. $\leq 65$ years old and $>65,0-1,2-14$, and $>14$ days before surgery, and compared using Fisher

Table 1 Patient interview questions

1. What do you understand the aims of the operation to be?

2. What alternatives do you understand there to be?

3. What risks do you understand the surgery to have? 
exact tests. A probability value less than 0.05 was considered statistically significant.

\section{Results}

\section{Patient characteristics}

All 153 patients about to or who had recently undergone lumbar decompressive surgeries had been consented with completed, dated, and signed consent forms of the respective institutions. The patient distribution in the 4 centres and their demographics are shown in Table 2 and Fig. 1. The mean age was 54 years. A bimodal distribution in age was noted, peaking at the 5 th and 8 th centiles. There was a non-significant male preponderance $(\mathrm{M}: \mathrm{F}=1: 0.87)$.

Compared to the three neurosurgical institutions, patients from the orthopaedic centre were consented for

Table 2 Patient distribution in four surgical centres

\begin{tabular}{|c|c|c|}
\hline Centre & $\begin{array}{l}\text { Number of } \\
\text { consent forms } \\
\text { reviewed }\end{array}$ & $\begin{array}{l}\text { Number of } \\
\text { patients } \\
\text { interviewed }\end{array}$ \\
\hline $\begin{array}{l}\text { Neurosurgery, John } \\
\text { Radcliffe Hospital, Oxford }\end{array}$ & 48 & 19 \\
\hline $\begin{array}{l}\text { Orthopaedics, Nuffield } \\
\text { Orthopaedic Centre, } \\
\text { Oxford }\end{array}$ & 29 & 26 \\
\hline $\begin{array}{l}\text { Neurosurgery, Queen } \\
\text { Elizabeth Hospital, } \\
\text { Birmingham }\end{array}$ & 49 & 40 \\
\hline $\begin{array}{l}\text { Neurosurgery, Charing } \\
\text { Cross Hospital, London }\end{array}$ & 27 & 23 \\
\hline Total & 153 & 108 \\
\hline
\end{tabular}

operations of more levels (2.0 vs $1.3, P=0.002)$ (see Fig. 2). Otherwise, there was no other difference in patient characteristics amongst the four centres.

\section{Intended benefits}

It was felt that "intended benefits" should be included in all consent forms: (1) to relieve pain (or discomfort) and (2) to improve (or prevent deterioration in) mobility. The level of documentation and patient recall for these intended benefits for the four centres are documented in Table 3. For pain relief, overall documentation was $96.7 \%$ and patient recall to open questioning was $75.0 \%$. On the other hand, only $24.8 \%$ of all consent forms explicitly documented improving mobility, with a corresponding patient recall of $29.6 \%$.

\section{Alternative treatments}

As not all hospital consent forms have "Alternative treatment" section, written documentation was not analysed. The level of patient recall for physiotherapy and epidural injection as an alternative to surgery is summarised in Table 4.

\section{Risks}

\section{Written documentation}

Overall, all four centres recorded operative risks on consent forms inconsistently with infection highest at $96.1 \%$ and recurrence lowest at $52.3 \%$ (see Fig. 3). Variation in documentation rates was significant $(P \leq 0.001)$ between all risks except for paralysis and sphincter disturbance,
Fig. 1 Demographics: age and sex

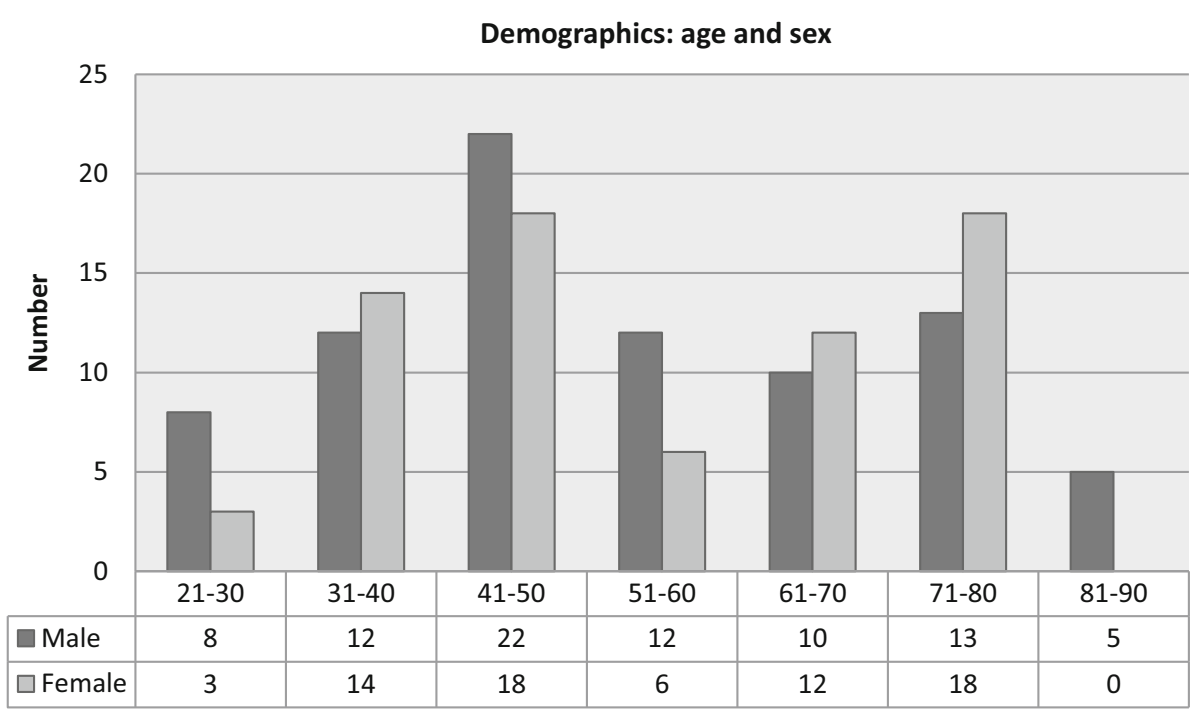


Fig. 2 Surgical levels

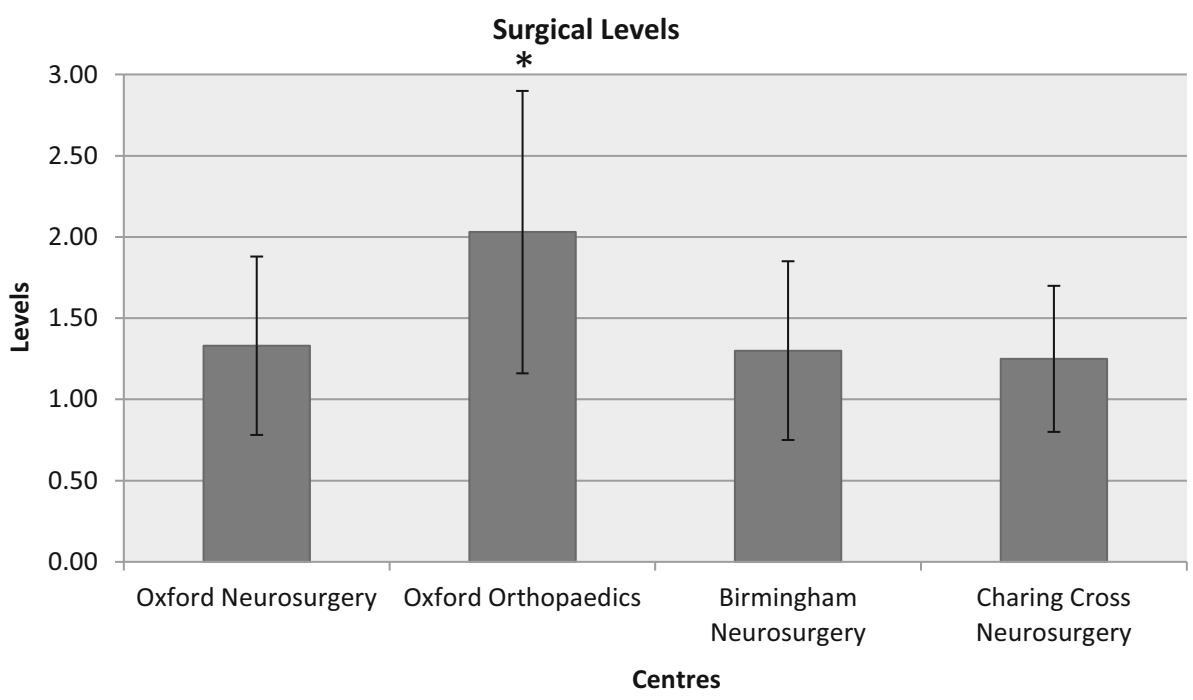

Table 3 Consent form documentation and patient recall of aims of surgery

\begin{tabular}{|c|c|c|c|c|}
\hline \multirow[t]{2}{*}{ Centre } & \multicolumn{2}{|l|}{ Relieve pain or discomfort } & \multicolumn{2}{|c|}{ Improve or prevent deterioration in mobility } \\
\hline & Written documentation (\%) & Patient recall $(\%)$ & Written documentation $(\%)$ & Patient recall $(\%)$ \\
\hline Neurosurgery, Oxford & $47 / 48(98.0)$ & $17 / 19(89.5)$ & $11 / 48(22.9)$ & $4 / 19(21.1)$ \\
\hline Orthopaedics, Oxford & $29 / 29(100.0)$ & $22 / 26(84.6)$ & $14 / 29(48.3)$ & $7 / 26(26.9)$ \\
\hline Neurosurgery, Birmingham & 48/49 (98.0) & $32 / 40(80.0)$ & $8 / 49(16.3)$ & $15 / 40(37.5)$ \\
\hline Neurosurgery, London & $24 / 27(88.9)$ & $12 / 23(52.2)$ & $5 / 27(18.5)$ & $6 / 23(26.1)$ \\
\hline Total & 148/153 (96.7) & 81/108 (75.0) & $38 / 153(24.8)$ & 32/108 (29.6) \\
\hline
\end{tabular}

Table 4 Patient recall of alternatives to surgery

\begin{tabular}{lcc}
\hline Centre & $\begin{array}{l}\text { Physiotherapy } \\
(\%)\end{array}$ & \multicolumn{1}{l}{$\begin{array}{l}\text { Epidural injection } \\
(\%)\end{array}$} \\
\hline Neurosurgery, Oxford & $0 / 19(0.0)$ & $0 / 19(0)$ \\
Orthopaedics, Oxford & $6 / 26(23.1)$ & $4 / 26(15.4)$ \\
Neurosurgery, & $5 / 40(12.5)$ & $2 / 40(5.0)$ \\
$\quad$ Birmingham & & \\
Neurosurgery, London & $4 / 23(17.4)$ & $3 / 23(13.0)$ \\
Total & $15 / 108(13.9)$ & $9 / 108(8.3)$ \\
\hline
\end{tabular}

paralysis and recurrence, dural tear, and infection. While the documentation rates of individual risks varied, such variations were consistent across regions and specialties, the only exceptions being higher documentation rates for haemorrhage $(P=0.001)$ and sphincter disturbance $(P=0.000)$ in Birmingham.

\section{Patient recall}

For patient recall, paralysis was the highest out of all risks (50.9\%, $P \leq 0.001)$. In contrast, recurrence was the lowest
(6.5\%, $P \leq 0.011$ ) (see Fig. 4). There was no variation between regions or specialties.

\section{Factors Affecting Patient Recall}

\section{Consenter seniority}

Trainees' written documentation of risks on consent forms did not deviate from consultants, except that they recorded haemorrhage (or bleeding) more frequently $(P=0.001)$ (see Fig. 5). As a result, patients recalled operative risks equally regardless of the consenter seniority (see Fig. 6).

The time between completion of consent form and surgery was divided into $0-1,2-14$, and $>14$ days. These three categories corresponded to consenting during admission, in pre-operative assessment clinics and outpatient clinics, when decision of surgery was made. For paralysis and recurrence, a longer consent-to-surgery time improved patient recall $[P=0.047, P=0.019$ respectively, Monte Carlo significant (1-sided)] (see Fig. 7). For other risks, patient recall was independent of the timing of consent. 


\section{Written documentation of consented risks}

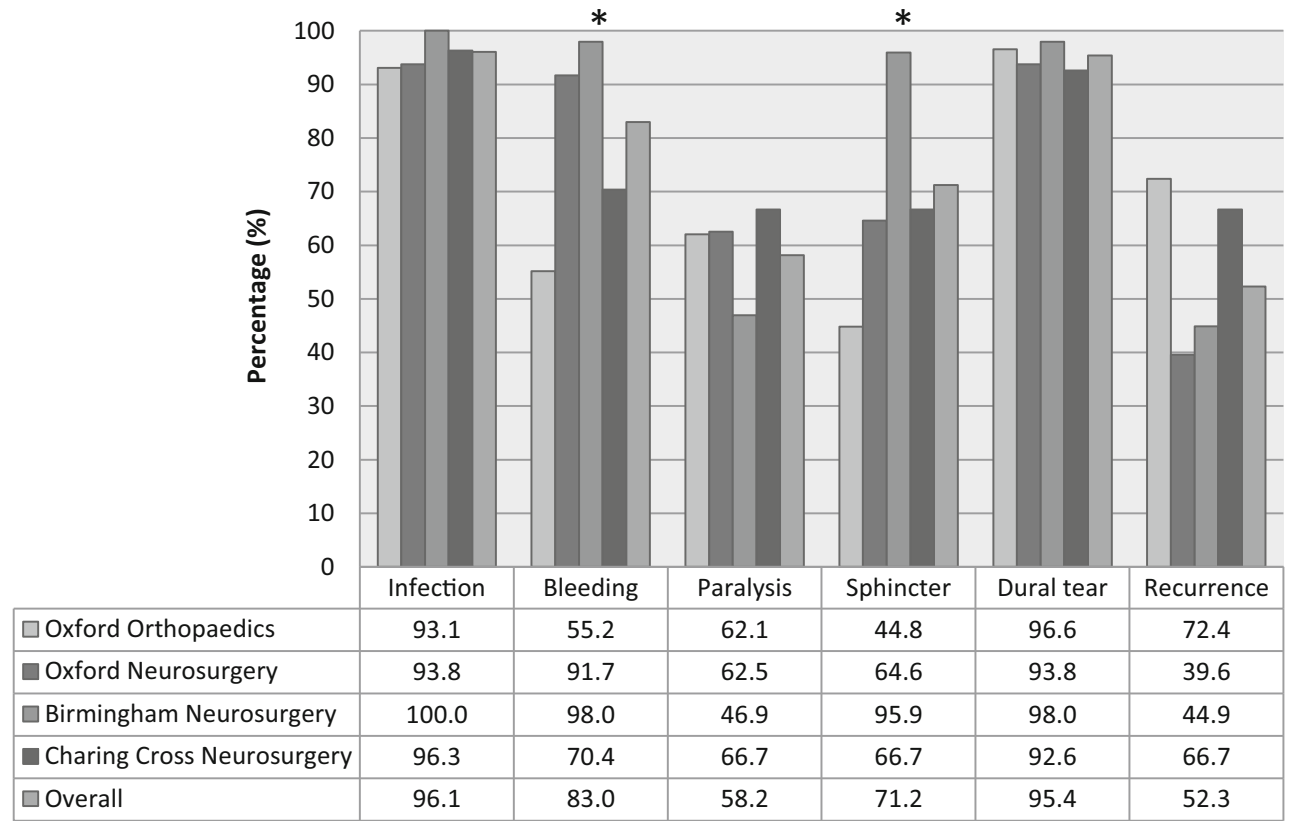

Fig. 3 Written documentation of consented risks at four centres

Fig. 4 Patient recall of risks

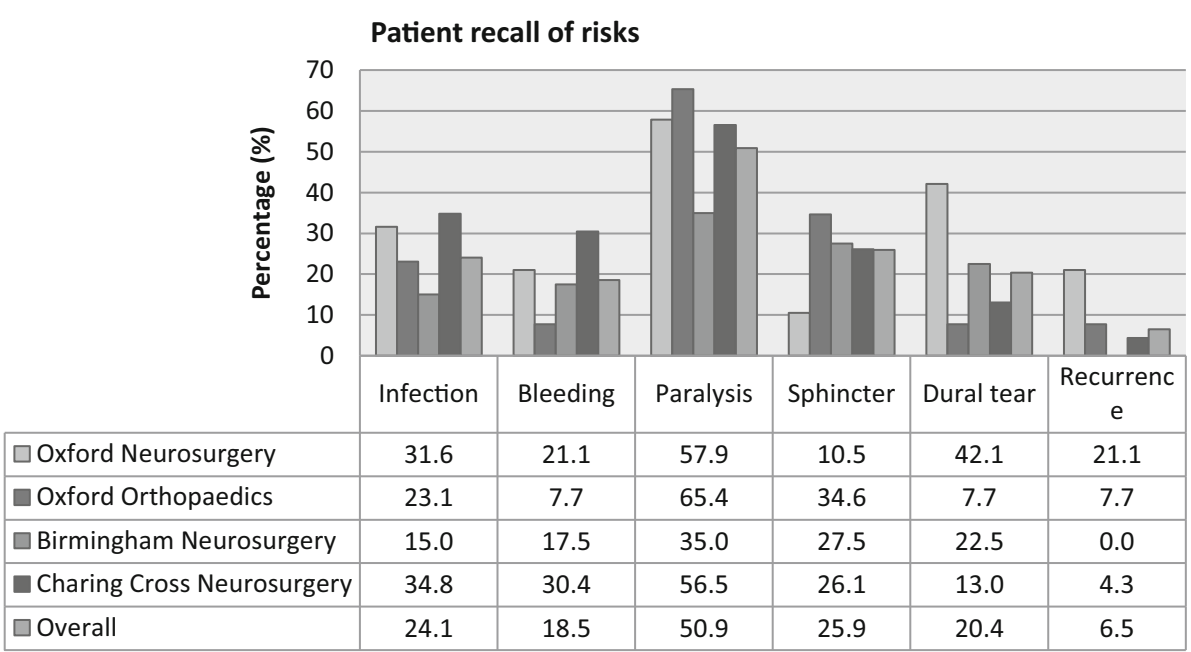

\section{Patient age}

Patients $<65$ years old had better recall then those $\geq 65$ years, significantly so for infection risk $(P=0.027)$ (see Fig. 8).

\section{Discussion}

In this study, we found that there was poor written documentation for paralysis (53.6\%), sphincter disturbance $(53.6 \%)$, and recurrence $(52.3 \%)$. The patient recall for all risk factors was lower than that documented. There was also low recall of alternatives to the treatment offered, with some centres not having this section included in the consent form.

Although patients in the current study had poor recall of risks, several factors were identified which could be used to improve recall. Krupp et al. [11] found that on average, patients remembered $18 \%$ of information $2 \mathrm{~h}$ after consenting for neurosurgical operations, with a mean recall of 4 risks out of 25 disclosed for spinal operations. However, in the current study, recall was significantly better for paralysis $(P=0.047)$ and recurrence $(P=0.019)$ if the 
Fig. 5 Written documentation: consultants vs trainees

Fig. 6 Patient recall: consultants vs trainees

Fig. 7 Time between consent and surgery and patient recall

\section{Written consents: consultants vs trainees}

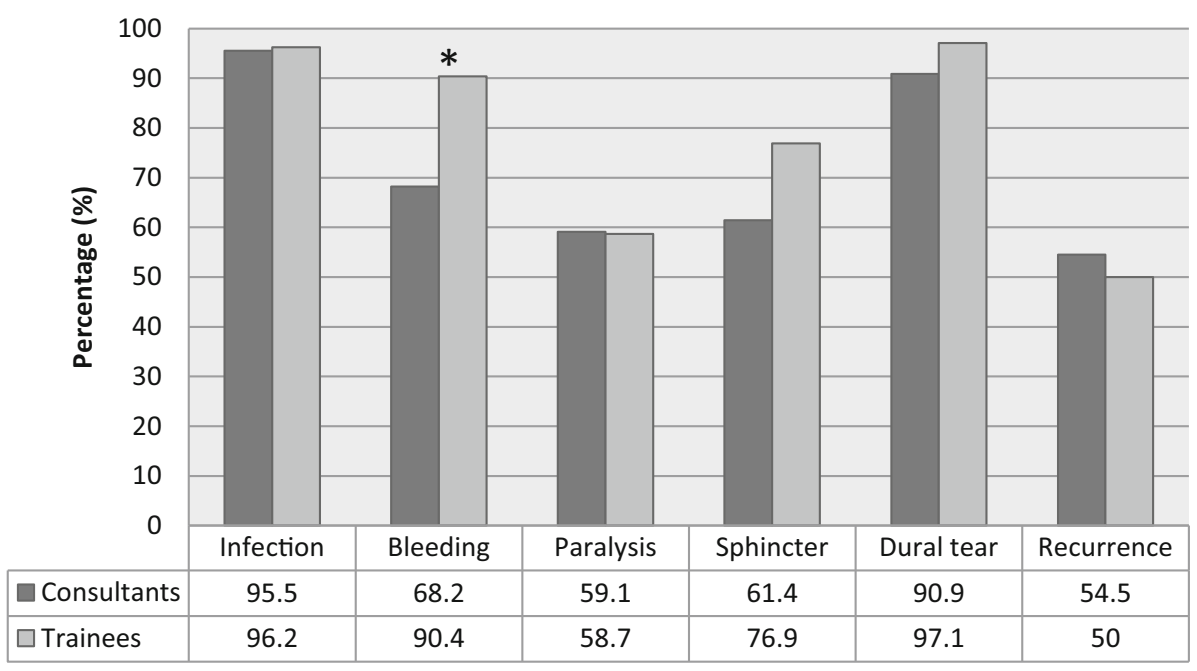

Patient recall: consultants vs trainees

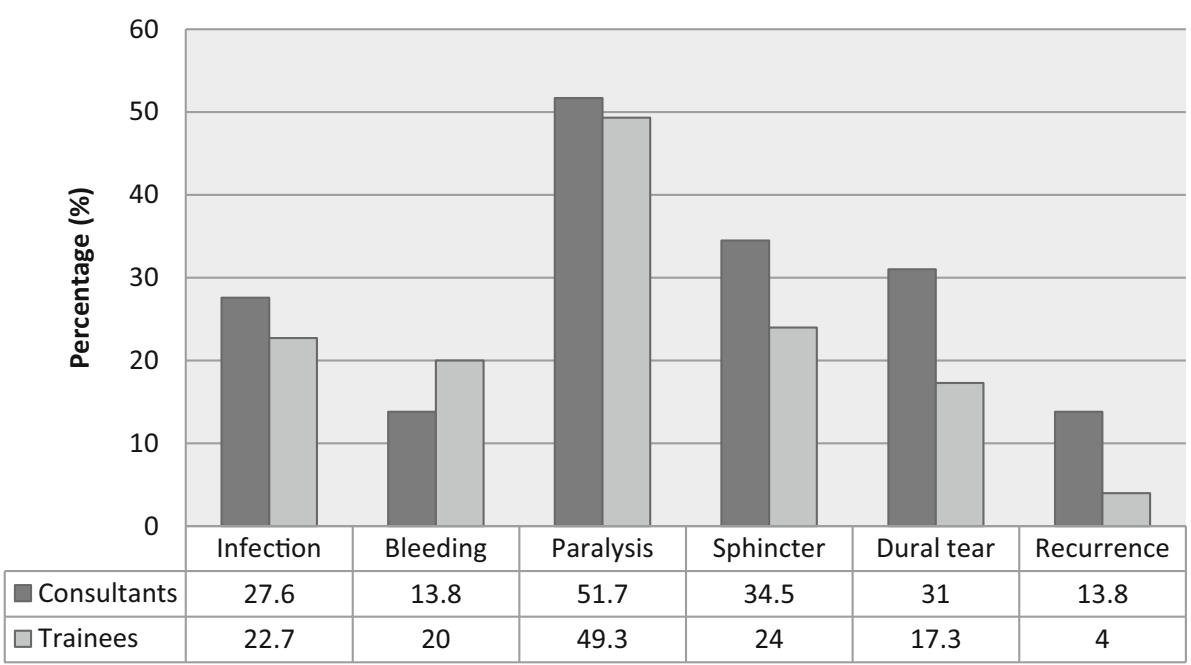

Does time between consent and surgery affect patient recall?

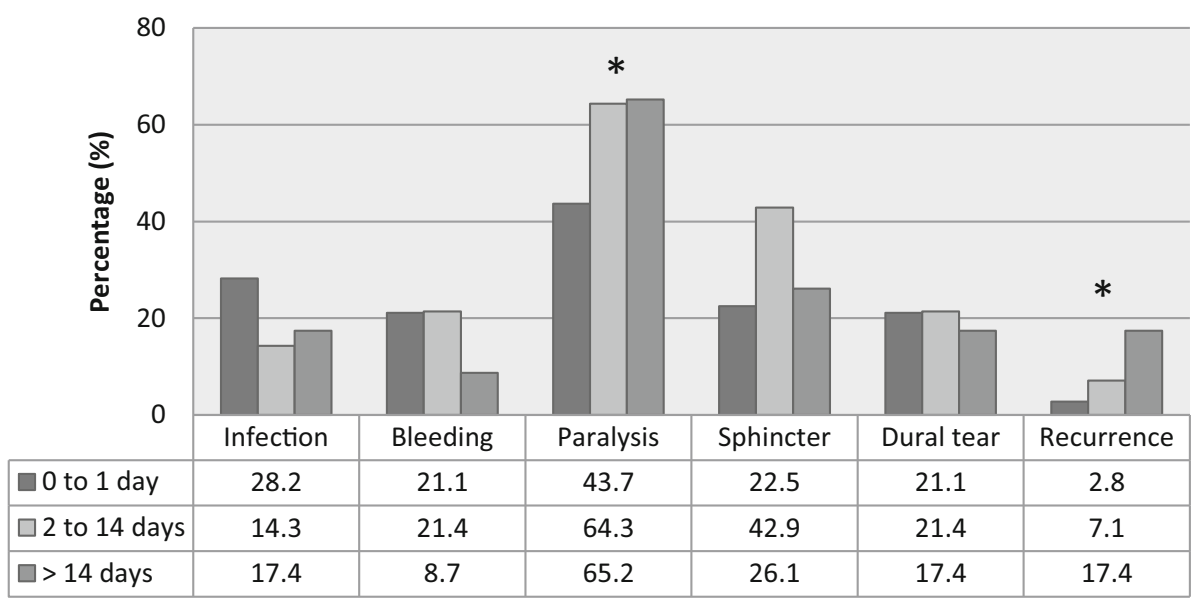


Fig. 8 Patient age and patient recall
Does age $(<65 \mathrm{v}\rangle=65)$ affect patient recall?

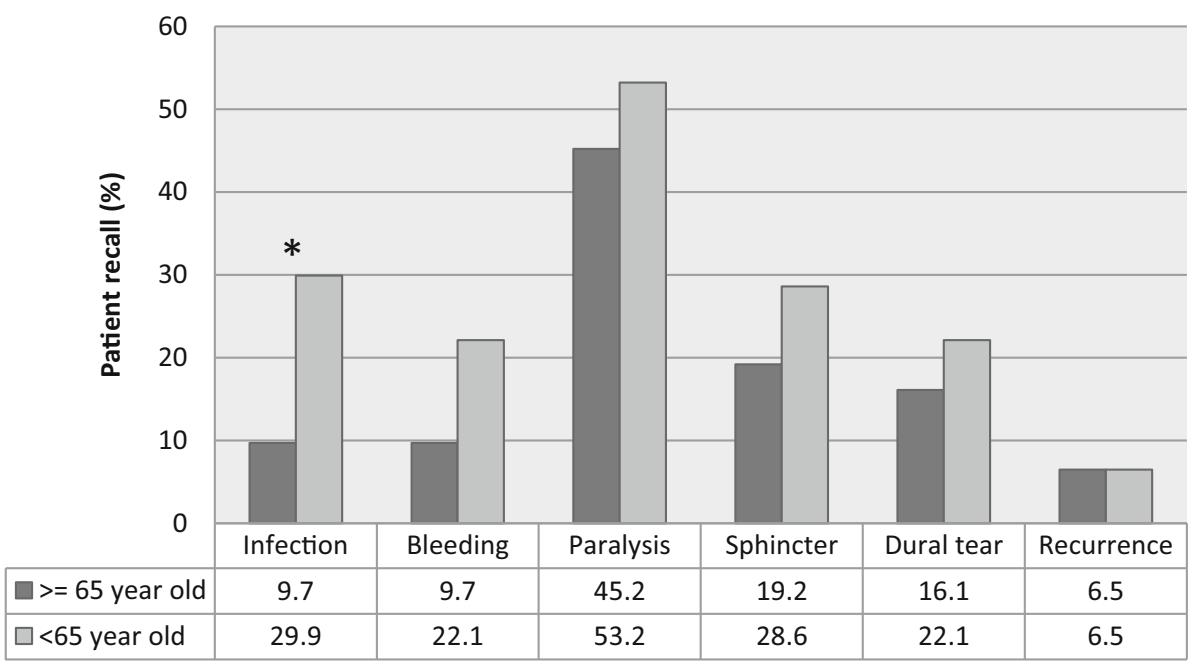

consent-to-surgery period was greater than 2 weeks. Unlike prior studies [11], we found that younger patients had greater recall for risks of the operation, significantly so for infection risk.

A number of factors were found to have no effect on recall; no link was found between written documentation of risk factors and recall of the risk factor nor was there any inter-centre variation, and therefore, there was no link between specialty and recall.

Interestingly, studies have suggested that patients are satisfied with giving consent even if they have not been adequately informed. Ellamushi et al. [12] used a patient questionnaire to assess consent in neurosurgery, and found that $100 \%$ of patients felt they had been informed with regard to the nature of their condition and the operation, with 97\% feeling, they had reached an informed decision. This was despite the fact that only $25 \%$ were informed of the general risks of surgery and anaesthetic, and 33\% about alternative treatments [12].

This failure of surgeons to document consent fully is not restricted to neurosurgery $[13,14]$. Nesargikar et al. [15] found that in colorectal surgery, only $36 \%$ were consented for pelvic nerve injury, with less patients consented for this in the over 70 years of age group compared to the under 50 years of age group, even though there is a bias for the elderly and women to be affected. Hoosein et al. [16] retrospectively analysed the notes of patients who underwent open inguinal hernia repairs and found that many serious complications were not adequately recorded, irrespective of the seniority of the person consenting the patient.

The UK GMC guidelines state that gaining consent for a procedure is the responsibility of the doctor providing the treatment. Should this not be possible, it may be delegated to someone with sufficient training and knowledge of the procedure [1]. However, our study, similar to Hoosein et al.
[16], found that increasing seniority did not increase patient recall for any risk. In fact, registrars were superior to consultants in recording bleeding as a risk in the written consent form.

Our study suggests that the current consent process is inadequate, with low patient recall of risks and poor documentation of some risks. Several alternatives to the typical consent form and process have been suggested in the literature. Barritt et al. [17] reported that procedure-specific consent forms were superior to generic consent forms for both knee arthroscopy and total knee replacement for patient understanding. Finch et al. [18] conducted a randomised control trial for consent for transurethral resection of prostate, comparing the conventional consent against procedure-specific consent forms produced by the British Association of Urological Surgeons. Whilst recall was suboptimal for both groups, greater recall of the 10 year reoperation rate was found in those with the procedurespecific consent forms [18].

Some have suggested that the current process of consent should be replaced with a patient focused approach, using a request for treatment (RFT) form instead. Unlike the traditional consent forms, the patient completes the RFT forms, including the procedure, benefits, risks, and complications, which helps document, and thereby address, any problems of understanding the patient that may have. Shokrollahi [19] outlined the benefits of request for treatment in a case study, suggesting that it will ensure provision of information of high enough quality to the patient and more robust documentation of the consent process. Using a request for treatment process would, however, lengthen the process of consent and may prove difficult for those who cannot read or write in English. Furthermore, difficulty may occur in assessing 'adequate' completion of the request for treatment form [20]. 
In light of the recent court rulings and guidelines from the Royal College of Surgeons, it may be pertinent to consider using procedure-specific consent forms or a request for treatment form to ensure adequate consent is given. Request for treatment forms may be particularly useful considering that they would increase time between consent and the surgery, which, based on the current study, would increase recall. The following other measures may be helpful but would not need to fully change the consent process: reviewing the consent process and test the patients' recall in the days preceding the surgery thus reinforcing the risks of the surgery; asking the patient to complete a questionnaire after the consent process to ensure adequate understanding; giving the patient duplicate copies of the consent form in advance of the surgery, with a detailed list of complications which they may review up to the surgery date.

Acknowledgements The authors thank Dipankar Nandi, James Wilson-MacDonald, Jeremy Fairbank, Spencer Harland, and Tom Cadoux-Hudson, who all acted as senior mentors for the studies in their respective centres.

\section{Compliance with ethical standards}

Conflicts of interest The authors declare that they have no conflicts of interest.

Open Access This article is distributed under the terms of the Creative Commons Attribution 4.0 International License (http://crea tivecommons.org/licenses/by/4.0/), which permits unrestricted use, distribution, and reproduction in any medium, provided you give appropriate credit to the original author(s) and the source, provide a link to the Creative Commons license, and indicate if changes were made.

\section{References}

1. General Medical Council (2008) Consent: patients and doctors making decisions together. 1-64. http://www.gmc-uk.org/gui dance/ethical_guidance/consent_guidance_index.asp. Accessed 1 May 2017

2. Wheeler R (2006) Consent in surgery. Ann R Coll Surg Engl 88(3):261-264. doi:10.1308/003588406X106315

3. Lupton M (2005) Informed consent: can a patient ever be fully informed? Curr Opin Obstet Gynecol 17(6):601-604. http://www. ncbi.nlm.nih.gov/pubmed/16258342

4. Reynard J, Marsh H (2009) The development of consent from Bolam to Chester: what you need to know and what your patients are entitled to know. BJU Int 103(11):1458-1461. doi:10.1111/j. 1464-410X.2009.08605.x

5. Sokol DK (2011) How can I avoid being used? BMJ 343:d7827. doi:10.1136/bmj.d7827

6. Garfield J (2005) Chester v. Afshar. A surgeon's view. Br J Neurosurg 19(2):120-121. doi:10.1080/02688690500145531

7. Leigh B (2006) Consent—an event or a memory? A judicial view. J Bone Jt Surg Br 88(1):16-18. doi:10.1302/0301-620X. 88B 1.16942

8. Wheeler R (2015) The new age of consent. Bull R Coll Surg Engl. 97(6):250-252. doi:10.1308/147363515X14272809071329

9. Lord J, President N, Hale L, President D, Kerr L, Clarke L (2015) Montgomery (Appellant) v Lanarkshire Health Board (Respondent) (Scotland), 1886-1887

10. Royal College of Surgeons (England) (2016) Consent: supported decision-making. https://www.rcseng.ac.uk/library-and-publications/ college-publications/docs/consent-good-practice-guide/ . Accessed 1 May 2017

11. Krupp W, Spanehl O, Laubach W, Seifert V (2000) Informed consent in neurosurgery: patients' recall of preoperative discussion. Acta Neurochir (Wien) 142:233-239. doi:10.1007/ s007010050030

12. Ellamushi HE, Khan R, Kitchen ND (2000) Consent to surgery in a high risk speciality: a prospective audit. Ann R Coll Surg Engl 82(3):213-216

13. Watts C (2008) Informed consent in neurosurgery: a case study. Surg Neurol 69(4):428-429. doi:10.1016/j.surneu.2007.09.037

14. Todd NV (2013) Medical negligence. Legal theory and neurosurgical practice: informed consent. $\mathrm{Br} \mathrm{J}$ Neurosurg 2014(28):209-213. doi:10.3109/02688697.2014.896872

15. Nesargikar PN, Kaur V, Cocker DM, Lengyel J (2010) Consenting for pelvic nerve injury in colorectal surgery: need to address age and gender bias. Ann R Coll Surg Engl. doi:10.1308/ 003588410X12628812459779

16. Hoosein MM, Towse H, Conn G, Stoker DL (2008) Consenting practice for open inguinal hernia repairs - are we failing to warn patients of serious complications? Ann R Coll Surg Engl 90(8):643-646. doi:10.1308/003588408X318165

17. Barritt AW, Clark L, Teoh V, Cohen AMM, Gibb PA (2010) Assessing the adequacy of procedure-specific consent forms in orthopaedic surgery against current methods of operative consent. Ann R Coll Surg Engl. doi:10.1308/003588410X1262881245 8257

18. Finch WJG, Rochester MA, Mills RD (2009) A randomised trial of conventional versus BAUS procedure-specific consent forms for transurethral resection of prostate. Ann R Coll Surg Engl 91(3):232-238. doi:10.1308/003588409X359277

19. Shokrollahi K (2010) Request for treatment: the evolution of consent. Ann R Coll Surg Engl 92(2):93-100. doi:10.1308/ 003588410X12628812458851

20. Wheeler R (2010) The evolution of consent. Ann R Coll Surg Engl 92(2):91-92. doi:10.1308/003588410X12628812458978 